BMC

Genomics

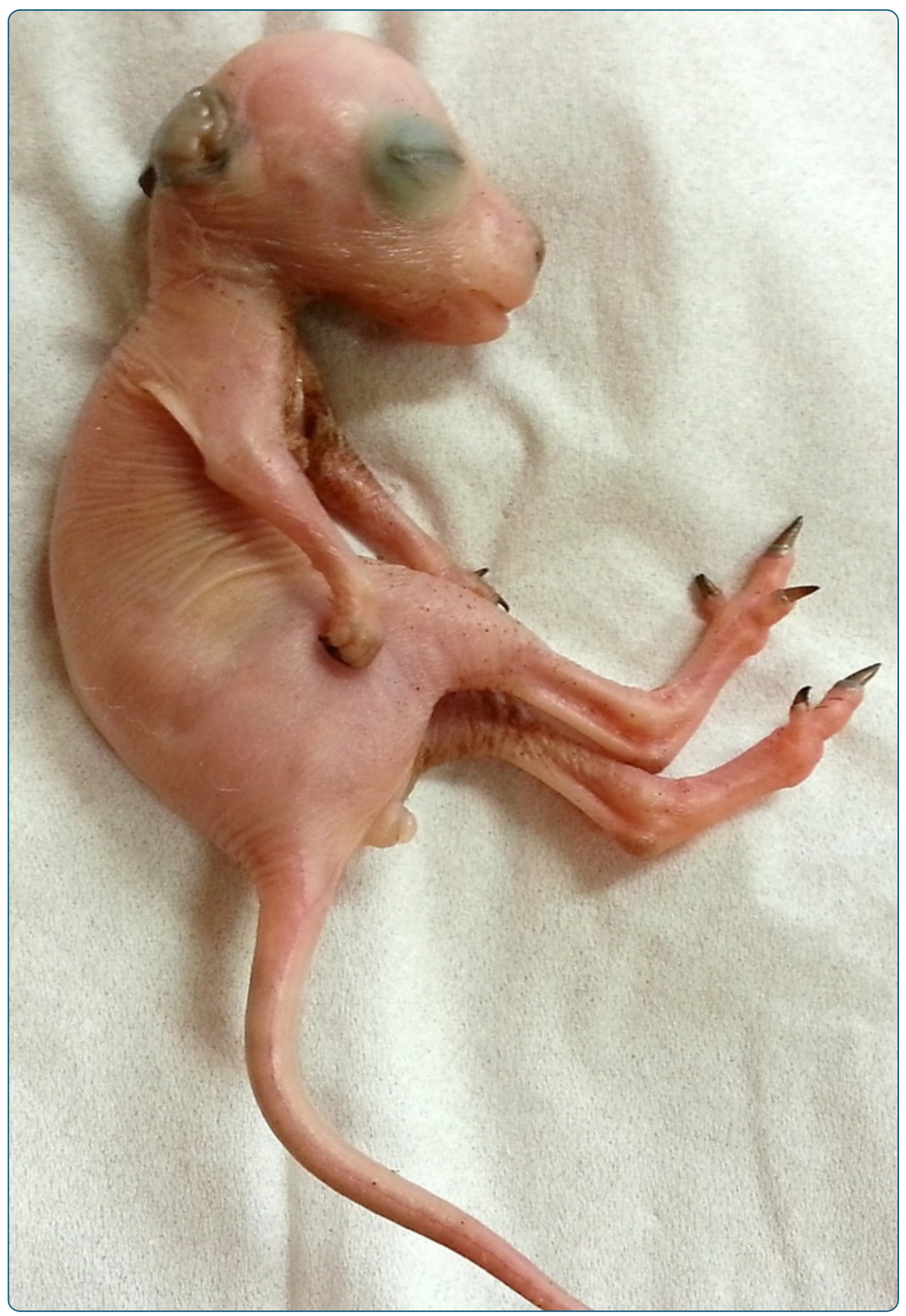

\title{
Differential temporal expression of milk miRNA during the lactation cycle of the marsupial tammar wallaby (Macropus eugenii)
}

Modepalli et al. 


\title{
Differential temporal expression of milk miRNA during the lactation cycle of the marsupial tammar wallaby (Macropus eugenii)
}

Vengamanaidu Modepalli ${ }^{*}$, Amit Kumar ${ }^{1}$, Lyn A Hinds ${ }^{2}$, Julie A Sharp ${ }^{1}$, Kevin R Nicholas $^{1}$ and Christophe Lefevre

\begin{abstract}
Background: Lactation is a key aspect of mammalian evolution for adaptation of various reproductive strategies along different mammalian lineages. Marsupials, such as tammar wallaby, adopted a short gestation and a relatively long lactation cycle, the newborn is immature at birth and significant development occurs postnatally during lactation. Continuous changes of tammar milk composition may contribute to development and immune protection of pouch young. Here, in order to address the putative contribution of newly identified secretory milk miRNA in these processes, high throughput sequencing of miRNAs collected from tammar milk at different time points of lactation was conducted. A comparative analysis was performed to find distribution of miRNA in milk and blood serum of lactating wallaby.

Results: Results showed that high levels of miRNA secreted in milk and allowed the identification of differentially expressed milk miRNAs during the lactation cycle as putative markers of mammary gland activity and functional candidate signals to assist growth and timed development of the young. Comparative analysis of miRNA distribution in milk and blood serum suggests that milk miRNAs are primarily expressed from mammary gland rather than transferred from maternal circulating blood, likely through a new putative exosomal secretory pathway. In contrast, highly expressed milk miRNAs could be detected at significantly higher levels in neonate blood serum in comparison to adult blood, suggesting milk miRNAs may be absorbed through the gut of the young.

Conclusion: The function of miRNA in mammary gland development and secretory activity has been proposed, but results from the current study also support a differential role of milk miRNA in regulation of development in the pouch young, revealing a new potential molecular communication between mother and young during mammalian lactation.
\end{abstract}

Keywords: Lactation, Marsupials, Micro RNA, Milk, Development, Mammary gland, Exosome

\section{Background}

MicroRNAs (miRNAs) are small RNAs involved in post-transcriptional regulation of target mRNAs, thereby regulating protein expression levels. miRNAs have crucial roles in regulating a wide range of cellular functions, such as cell differentiation, proliferation and cell death $[1,2]$. Recent studies have shown that secretory miRNAs are found in body fluids including breast milk [3], saliva [4], plasma [5] and urine [6]. The presence of circulating or secreted miRNAs in these body fluids has suggested that

\footnotetext{
* Correspondence: vnm@deakin.edu.au

'School of medicine, Deakin University, Pigdons Road, Geelong, Vic, Australia Full list of author information is available at the end of the article
}

secretory miRNAs may function in extracellular cell to cell signalling and participate in intercellular regulation of cell function [7]. It has also been reported that secretory miRNAs, and in particular milk miRNA, may be secreted inside small vesicles called exosomes [3]. Exosomes are small lipid-bilayer membrane vesicles, which are released by cells into the extracellular environment and carry various components including peptides, protein, mRNAs and miRNAs [8]. Exosome packaging is considered as a key factor for the stability of secretory miRNAs in the degrading conditions of the extracellular environment [9]. Apart from being secreted in exosomes, milk miRNAs may also be secreted by an alternative mechanism through milk fat globules [10]. Production of milk is a complex 
process; milk is composed of various bioactive components supporting early development of the neonate $[11,12]$. Therefore it is important to fully understand the functional role of miRNA in milk. Expression studies of milk miRNAs have so far been reported in several eutherian species including human [13], bovine [14], pig [15] and goat [16], and have shown that a number of these miRNAs are related to immune regulation, suggesting they may regulate the immune system of sucklings. In addition, miRNAs are known to have important roles in various biological processes, including organogenesis and morphogenesis during fetal development. Gene knockout studies in laboratory models such as zebra fish and mouse have demonstrated that miRNAs are involved in development through post-transcriptional regulation of mRNA expression $[17,18]$.

In mammals, the change from intrauterine to extrauterine life is a major transition that is exclusively supported by maternal milk provision. Limited development of neonates is observed after a short gestation in primitive mammals like marsupials and monotremes, and milk has a vital role in supporting the development of immature new born during their early postnatal life [19]. During evolution of mammals, marsupials and eutherians have adopted different reproductive strategies which have given rise to a marked difference in maturation at birth [20]. Eutherians, including humans, undergo a long gestation period allowing greater foetal development in utero and their composition of milk does not change significantly except for the short period of colostrum production at the onset of lactation [21]. In contrast, marsupials such as the tammar wallaby (Macropus eugenii) have a short gestation followed by a long lactation, and the composition of milk changes significantly throughout the lactation cycle to provide factors for growth and development of the immature neonate $[12,20]$. As a result of a short gestation and long lactation period, a significant part of development and growth of the marsupial young occurs postnatally during early lactation [22], and signalling factors necessary for development of the neonate may be secreted by the marsupial mammary gland [23]. Mammalian neonates generally receive immune protection from milk (or colostrum) immediately after birth. In marsupials in particular, the newborn, which does not receive any passive immunity during foetal development, lacks a mature immune system and this renders them more vulnerable to pathogenic infections and therefore they are highly dependent on maternal immune source via milk for adequate protection [24,25].

Studies of the lactation systems of marsupial such as the allied rock wallaby (Petrogale assimilis) [26], the north American opossum (Didelphis Virginiana) [27] and the tammar wallaby (M. eugenii) [12,28] shown significant changes in their milk composition throughout lactation in marsupials. The tammar wallaby is the one of most studied marsupials and its lactation period is divided into three phases based on the composition of the milk, growth and behaviour of the young (phase $2 \mathrm{~A}$, phase $2 \mathrm{~B}$ and phase 3 , while gestation is phase 1) [29]. The tammar wallaby gives birth to a single altricial young after 28 days of gestation (phase 1 of the reproductive cycle). The new born weighs approximately 440 milligrams at birth [30]. During the early phase of lactation (Phase2A, 100 days), the young is permanently attached to the teat and the mother secretes dilute milk with a low concentration of protein and lipids but a high concentration of complex carbohydrates [31]. In mid-lactation (phase2B, day 100 to 200) the young remains in the pouch without being permanently attached to the teat and milk composition remains similar although changes in milk protein composition have been observed [32]. During the final stage of lactation (Phase3, day 300-325), the pouch young begins feeding on vegetation but still consumes milk from the mother. During this phase of lactation, the milk becomes rich in protein and lipids with a reduction in the concentration of carbohydrates [33]. The continuous change in the composition of milk proteins has important roles for the development of the pouch young [34] and therefore the tammar provides an exceptional model to correlate milk composition with the defined developmental changes of joeys during lactation, and the identification of new activates in milk associated with molecular signals [35].

The aims of the present study were first to confirm the presence and identify small RNA in marsupial milk, particularly focusing on regulatory miRNA, and to quantitatively profile the dynamics of marsupial milk miRNA expression during the lactation cycle. In addition, this investigation compared miRNA in lactating mothers milk and circulating blood serum in order to investigate the possibility of transfer of blood miRNA into milk. Finally the study evaluated the putative transfer of milk miRNAs from the mother to the circulatory system of the neonate. Overall, the study supports the concept that milk miRNA represent new signalling agents in the molecular relationship between mother and young that has evolved in mammals.

\section{Results}

Tammar wallaby milk contains RNA and is enriched in miRNA

First, to confirm the presence of RNA in marsupial milk, RNA was purified from tammar wallaby milk collected at day 250. The results confirmed that tammar milk contains significant quantities of total RNA $(319.28 \mu \mathrm{g} / \mathrm{ml})$ and small RNA (sRNA). Profiling on the Bioanalyzer (Figure 1A) showed that a large proportion of milk total RNA was small RNA 83\% $(265.06 \mu \mathrm{g} / \mathrm{ml})$ with miRNA representing 


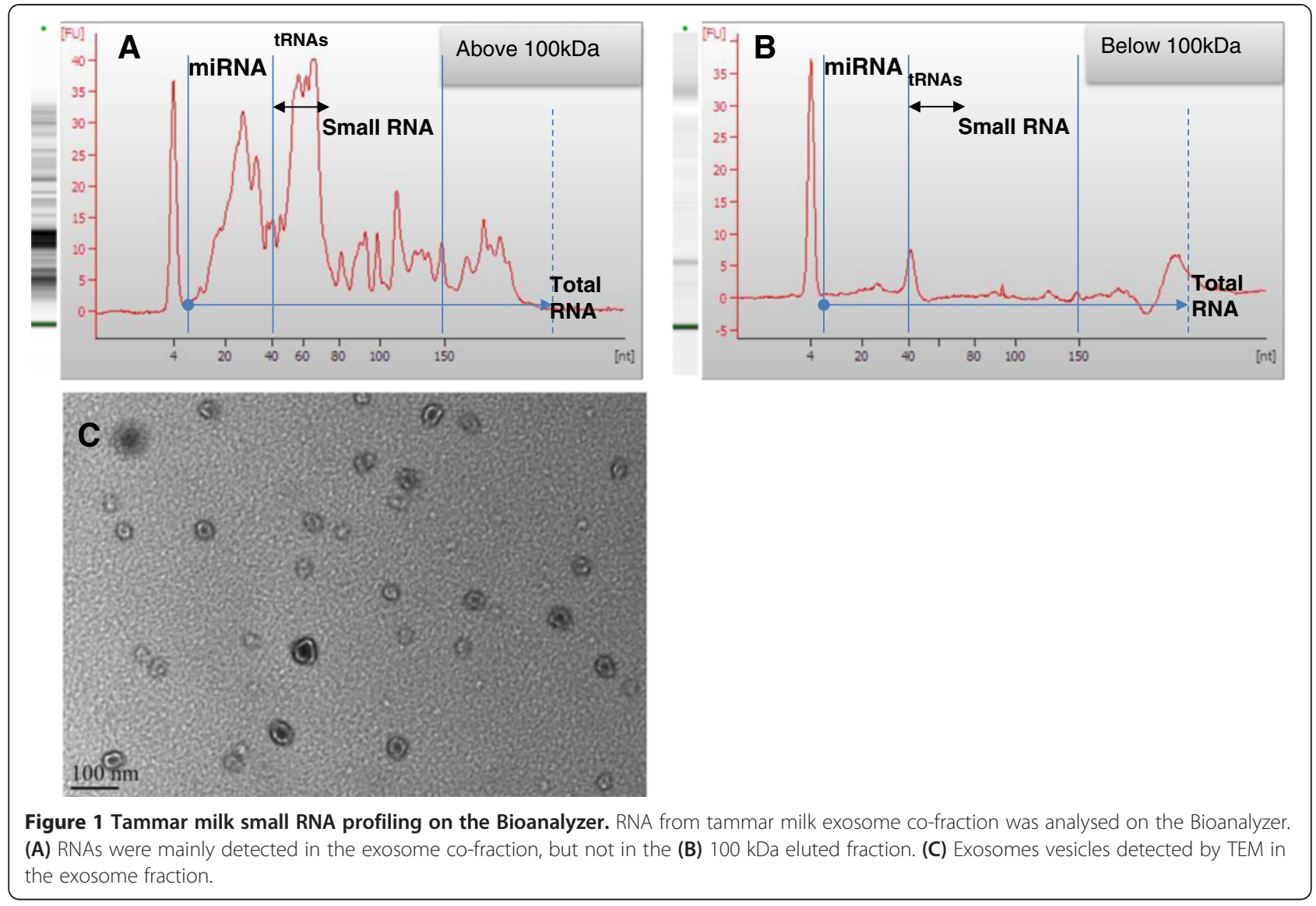

approximately $66 \%$ of total milk RNA $(210.65 \mu \mathrm{g} / \mathrm{ml})$. However, these values may be considered approximate, as the results are obtained from milk that has been through a single freeze-thaw cycle, even though the milk exosomal miRNAs were shown to be partially stable during multiple freeze-thaw cycle $[3,36]$.

\section{Tammar wallaby milk miRNA co-purifies with exosome-like vesicles}

To analyse the compartmentalisation of small RNA in milk, tammar milk was fractionated by a series of ultracentrifugation steps followed by filtering as described in methods. Small RNA was shown to remain in the supernatant after ultracentrifugation at 60,000 $\mathrm{g}$ for 1 hour and did not pass through a $100 \mathrm{kDa}$ filter (compare Figure $1 \mathrm{~A}$ and Figure 1B), suggesting that the RNA is likely associated with either high molecular weight complexes or small vesicles. TEM microscopy of the RNA enriched fraction (Figure 1C) revealed that the fraction was also enriched in vesicles of $40-80 \mathrm{~nm}$ diameter, exhibiting similar structure to exosomal vesicles previously reported in milk preparations from eutherian species $[13,36]$. These results suggest that RNA is most likely transported within exosomes in tammar milk, although we cannot exclude association with large protein complexes. Further, to analyse the stability of miRNA in the milk exosome fraction under conditions similar to the stomach environment, the exosome preparations were incubated at $\mathrm{pH} 4$ and $\mathrm{pH} 1.5$, and treated with RNAse (Figure 2). Free synthetic exogenous miRNAs were added to the preparation as a control. The results showed that milk miRNAs were more stable in acidic medium and highly resistant to RNAse treatment in comparison to exogenous miRNAs. This suggests that milk miRNAs in exosome were protected, supporting exosome packaging as a likely factor for their stability.

\section{Tammar wallaby milk miRNA profiling}

In order to characterise the small RNA population of tammar milk, seven small RNA libraries were sequenced on an Illumina hiseq 2000 sequencer. RNA samples were isolated from milk at various stages of lactation and from two additional samples isolated from the blood serum of lactating wallabies also used for milk collection at 118 and 175 days of lactation. Small RNA library sequencing reactions produced from 9 to 13 million raw reads, which were cleaned by removal of low quality reads, reads contaminated with 3 prime and 5 prime adaptor sequences, adaptor only sequences and sequences shorter than 18 nucleotides (Table 1). A total of 4 to 13 million high quality reads were recovered from the libraries. The 


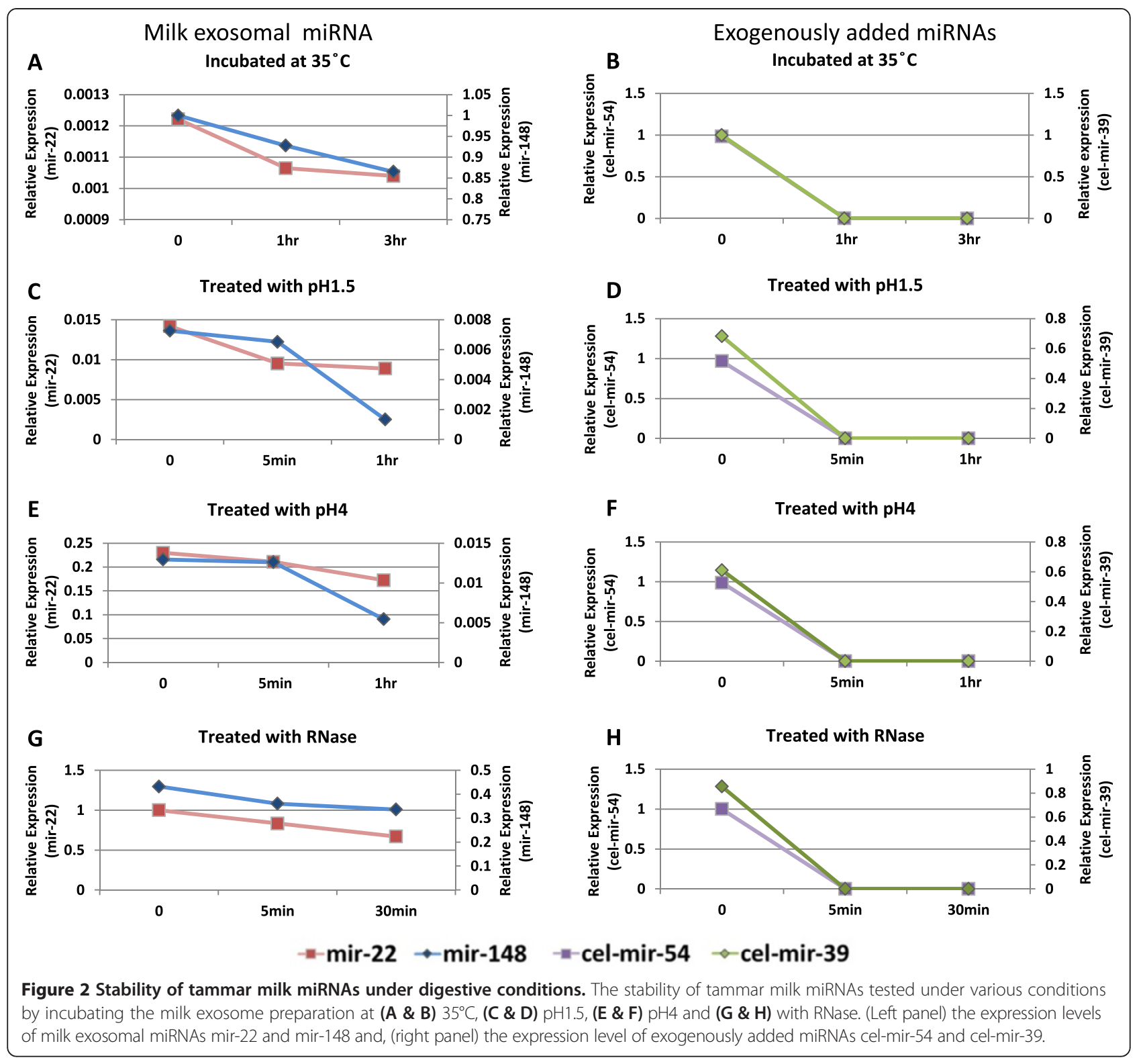

sequence length distribution of small RNA showed the highest abundance at $22 \mathrm{nt}$, indicating miRNA-like sequences were the most abundant sequences identified in the majority of samples, representing from 20 to $62 \%$ of total RNA sequence reads (Figure 3 and Table 2). Milk samples from Day-72 and phase-3 also showed a high proportion of 30-31 nt sequences mainly representing transfer RNA fragments.

Milk miRNA profiles change during the lactation cycle of the tammar wallaby

As discussed earlier, the tammar lactation cycle is divided into three main stages; phase 2A (up to day 100), phase 2B (from day 100-200) and phase 3 (after day 200), with phase 1 corresponding to the period of gestation. While annotated miRNA from serum consistently represented $60 \%$ of small RNA sequences, this proportion varied for 20 to $60 \%$ of sequences from milk (Table 2). In contrast, milk samples after day 72 of lactation had apparently a slightly more diverse miRNA population than serum despite the fact that milk and serum samples were collected from the same lactating female at day 118 and day 175 (Table 2). Interestingly, this was due to a larger set of newly predicted miRNA from milk. Overall, the number of small RNA sequences, unique reads and miRNAs expressed in milk samples showed some variability due to contamination by tRNA fragments as observed above for Day-72 and phase-3 samples and other experimental factors. Therefore miRNA only sequences annotated by miRanalyzer were collected and 
Table 1 Processing of wallaby small RNA libraries

\begin{tabular}{llllllll}
\hline & Day-35 & Day-72 & Day-118 & Day-175 & Day-250 & D-118 serum & D-175 serum \\
\hline Total reads & 12381908 & 12134643 & 13784187 & 12309932 & 13709829 & 14309026 & 10205531 \\
High quality & 12335856 & 12089154 & 13751725 & 12280357 & 13658689 & 14256868 & 10180431 \\
3'adapter & 92168 & 88219 & 59397 & 64848 & 52910 & 72041 & 89445 \\
Insert & 439041 & 323346 & 237928 & 81011 & 79542 & 194066 & 232346 \\
5'adapter & 101546 & 18404 & 33582 & 54636 & 44400 & 105075 & 99390 \\
$<\mathbf{1 8}$ nt & 1821675 & 376879 & 2041588 & 1288530 & 1392025 & 440562 & 669988 \\
polyA & 5 & 186 & 311 & 87 & 190 & 6 & 63 \\
Clean reads & 9881421 & 11282120 & 11378919 & 10791245 & 12089622 & 13445118 & 9089199 \\
\hline
\end{tabular}

proportion-normalised to allow a more relevant comparison of miRNA populations; by dividing the total number of reads annotated for each miRNA by the total number of miRNA reads annotated in respective samples (see Additional file 1).

The ten most highly abundant miRNAs in milk at five lactation time points and blood serum samples at day 118 and 175 of lactation are summarized in (see Additional file 2). MiR-191 and miR-184 were the most abundant miRNAs in milk from day 35 to day 118. MiR-191 was also present in a very high proportion in the blood serum of mothers. MiR-184 was highly abundant in phase-2A and early phase-2B. Three miRNAs of the let-7 family (7f, $7 \mathrm{a}$ and $7 \mathrm{i}$ ) were also among the top ten miRNAs expressed during the lactation cycle. MiR-181 was consistently in the 6 most abundant miRNAs in all milk and serum samples. MiR-148 showed a gradual increase in proportional abundance from early lactation to the end of phase-2B and was the most highly abundant miRNA at day-175. MiRNA-375 also showed a gradual increase in proportional abundance from early lactation with a peak in phase 3 (Figure 4).
Milk miRNA expression data suggested that a number of miRNAs were expressed differentially during lactation. Based on the quantification of sequencing data we selected mir-148, mir-22, mir-30a and mir-141, to confirm this differential temporal expression during the lactation cycle by qRT-PCR (Figure 5). As shown in Figure 4 these miRNAs were also shown to be differentially expressed in milk collected at similar time points of lactation from at least 3 different animals at each time point, excluding milk from the animals used for sequencing. The results correlated well with those from quantitative RNA sequencing, therefore individual PCR confirmed differential temporal expression of all the tested miRNA in milk collected from all other animals.

\section{Co-expression of wallaby milk miRNA}

Hierarchical clustering of normalised miRNA proportion profiles showed blood samples were closely grouped together while milk samples were grouped on a different branch of the dendogram (Figure 6A). In order to further identify trends in the co-expression of milk miRNA during the lactation cycle, normalised miRNA quantification

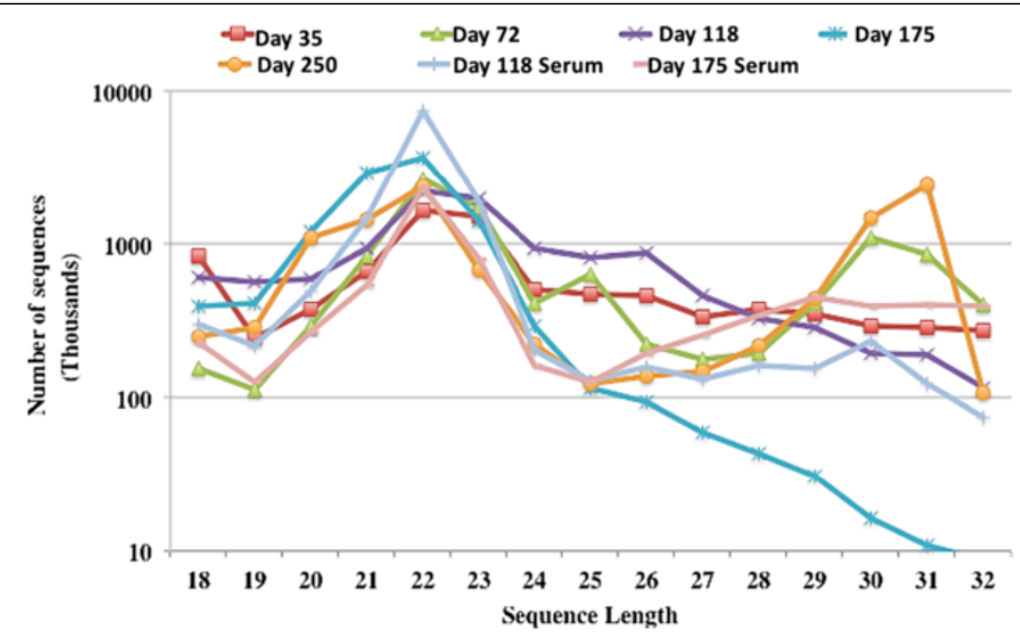

Figure 3 The distribution of small RNAs of various lengths (18-32 bp) sequences. Small RNAs were isolated from the tammar milk day 35 , day 72, day 118, day 175 and day 250 lactation, and small RNA isolated from tammar lactation mother serum at day 118 and day 175. 
Table 2 MicroRNA analysis using miRanalyzer

\begin{tabular}{llllllll}
\hline & Day-35 & Day-72 & Day-118 & Day-175 & Day-250 & Day-118 serum & Day-175 serum \\
\hline Total reads & 6781022 & 7084407 & 9559993 & 10596179 & 6664261 & 12360382 & 4776956 \\
Unique reads & 28968 & 52333 & 72537 & 40811 & 48558 & 22639 & 34143 \\
\% reads aligned to miRNAs & 25.80 & 50.30 & 20.80 & 37.50 & 62.30 & 62.30 & 58.50 \\
\% reads aligned to genes & $0.00 \%$ & $0.00 \%$ & $0.00 \%$ & $0.00 \%$ & $0.00 \%$ & $0.00 \%$ & $0.00 \%$ \\
miRNA known & 49 & 90 & 60 & 85 & 90 & 77 & 76 \\
Predicted miRNAs & 45 & 131 & 89 & 101 & 141 & 60 & 55 \\
Total miRNAs & 94 & 221 & 149 & 186 & 231 & 137 & 131 \\
\hline
\end{tabular}

data were clustered into 5 groups or clusters by the Self Organizing Tree Algorithm (SOTA) implemented in $\mathrm{MeV}$ (Version 4) software, using default settings (Figure 6B). The proportion of miRNAs in each cluster is represented in Table 3. Milk miRNAs in cluster 1 had more variable relative concentration profiles dominated by a biphasic profile with increased proportions in early phase $2 \mathrm{~A}$ and during phase $2 \mathrm{~B}$. This group included let-7 family miRNAs members let-7a, let-7f and let-7i. Cluster 2 was the smallest cluster encompassing only 7 miRNAs. The highest expression values were reported on day-35 with decreasing relative expression thereafter. In cluster 3, miRNAs were highly represented up to day 118 with a gradual decrease in late lactation phases $2 \mathrm{~B}$ and 3 . In cluster 4, miRNAs showed comparable expression across the whole lactation cycle, including miR-191 and mir10b, some of the three most highly expressed miRNA in all samples. Cluster 5 contained the highest number of miRNAs (41\%). This cluster consisted mainly of milk miRNAs expressed at all stages of lactation with consistent proportional increase from early to late lactation.
The most notable miRNAs in this group were mir-375, mir-30a and mir-148. The proportion of miRNAs in each cluster is represented in Table 3.

\section{Comparison of miRNA in wallaby milk and maternal serum}

As only minute amount of milk could recovered during the earlier stages of lactation (50 to $300 \mu \mathrm{l}$ ) and to minimize cost, we decided to target more specifically the transitional from phase $2 \mathrm{~B}$ to phase 3 . Lactating mothers at day 118 and day 175 were used to compare miRNA profiles in milk and blood serum of the lactating mother. Overall a similar number of specific miRNAs were identified in milk (86 miRNA) and serum (82 miRNA). However, miRNA composition was widely different in milk and serum (see Additional file 3). Further analysis revealed that 13 miRNAs were milk specific and 9 were serum specific (Table 4). Most of the serum specific miRNAs had low read counts with the highest number of reads mapping to miR-1 (731 reads). In contrast, milk specific miRNAs showed comparatively high expression with, for example,

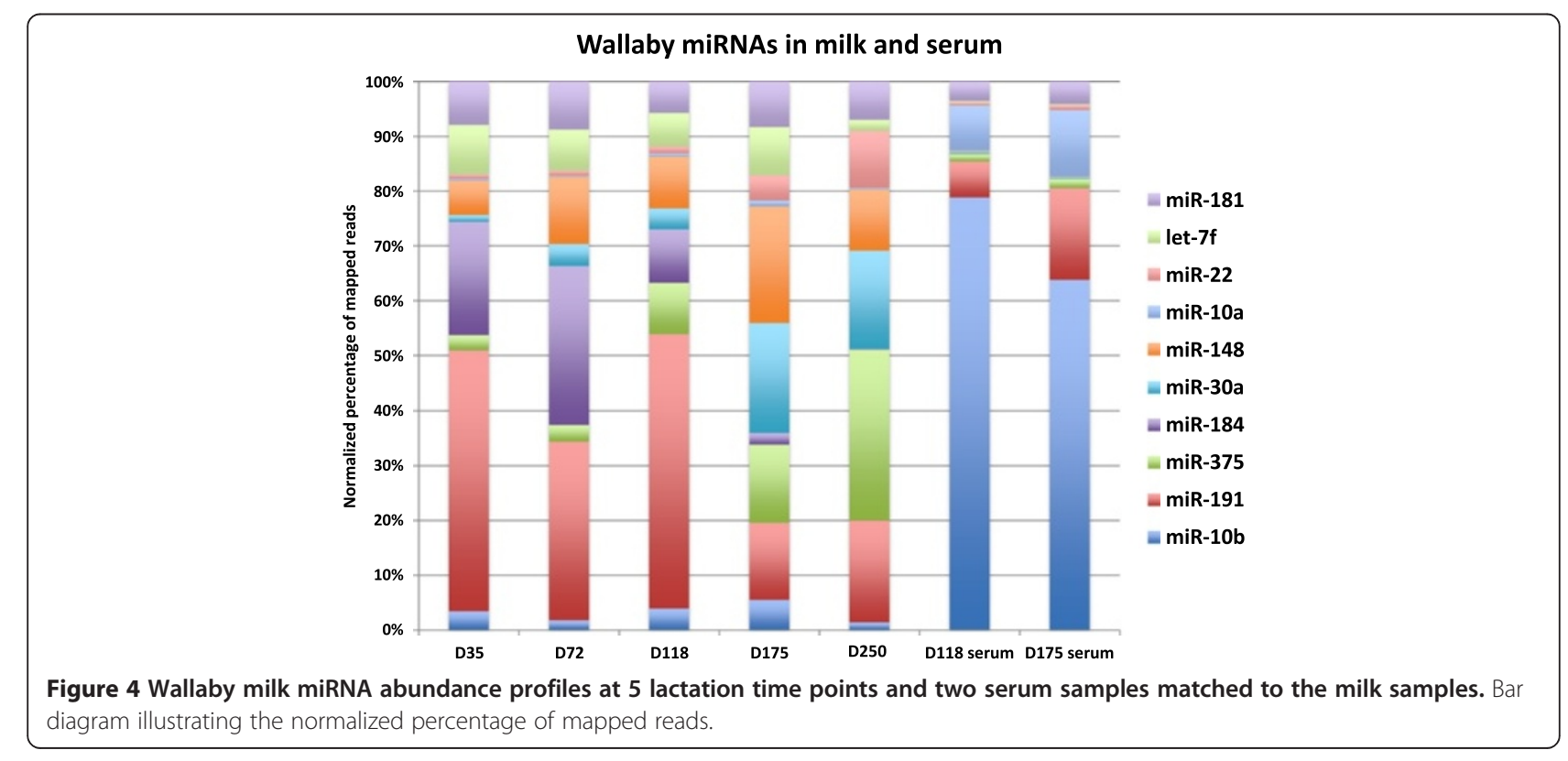



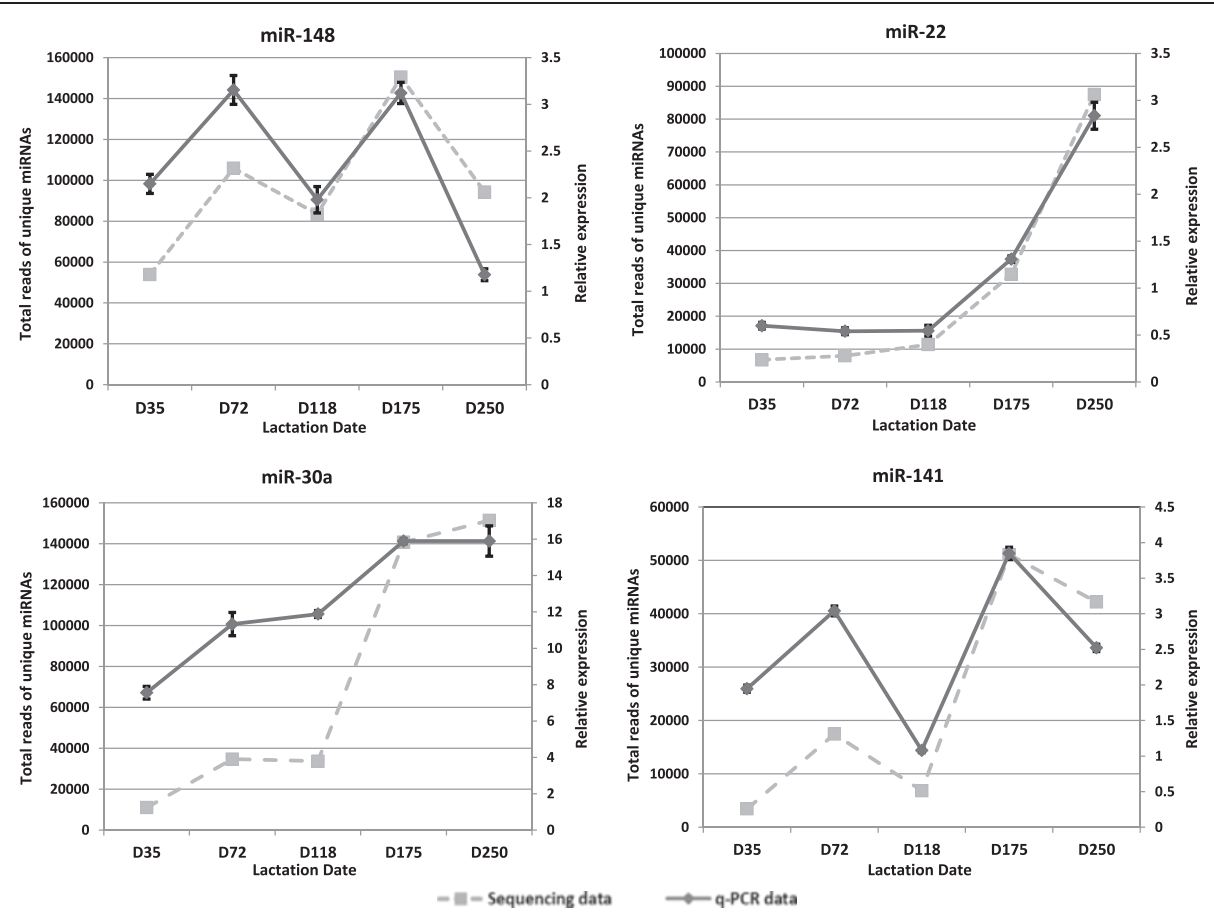

Figure 5 Tammar milk miRNA expression pattern during lactation. The expression profiles of highly abundant tammar milk miRNAs were correlated between the $\mathrm{q}-\mathrm{PCR}$ and sequencing data Values are means \pm SD.

miR-204 represented by 58,142 reads. As shown in Table 4, other miRNAs with over 500 read counts were miR-200b, miR-200c, miR-200a-5p and miR-1549. Interestingly, the genomic locations of miR-200a and miR-200b genes are closely located within a chromosomal cluster. These results suggest co-expression and co-secretion of these closely linked miRNA. The most abundant milk-enriched and serum-enriched miRNAs are listed in Table 5 with their respective normalized expression values. While miR-191 was most highly abundant in milk during the first three time points of lactation (phase 2A), its expression decreased on lactation day-175 (phase 2B) and at the same time, showed a marked increase in serum of mothers. Although the data does not address the specificity and dynamics of circulating miRNA exchanges between maternal blood and milk, and it remains to fully establish if miR-191 is instead no longer transferred from blood into milk from day 175 , this observation, together with the general disparity of milk and serum miRNA profiles, suggests that there is no direct correlation between serum and milk miRNA contents. Therefore the data strongly supports the likelihood of local biogenesis of secretory miRNA by the mammary gland rather than transfer from blood into milk.

\section{Quantification of milk related miRNAs in pouch young and adult blood}

To analyse the distribution pattern of milk related miRNAs in blood of the pouch young, a subset of miRNAs which were identified above as highly expressed in tammar milk compared to mother serum (mir-148, mir-22, mir-141 and mir-30a) was selected for validation by quantitative PCR. Using the stem-loop RT-PCR method, these miRNAs were quantified in serum of pouch young at lactation day 30, 80, 130, 150 and weaned juvenile (adult), a significant increase in levels of expression relative to adult $(P<0.05)$ (Figure 7$)$. Generally, these miRNAs were in higher proportion in pouch young serum than in the weaned juvenile (adult). The result suggests that highly expressed milk miRNA may transfer to the pouch young serum during early development when the immature gut may allow passive absorption of milk miRNA. However, we cannot exclude independent endogenous biogenesis of miRNAs in pouch young during early development and this would need to be assessed more directly in future experiments.

\section{Discussion}

In recent years, advances in sequencing technologies have allowed the identification of a miRNA population in eutherian milk. In this study for the first time, we have confirmed there are also significant quantities of miRNA present in marsupial milk using the tammar wallaby model.

Milk provides optimal postnatal nutrition for newborn mammals [37]. Milk composition has been investigated in many species $[34,38,39]$ and the milk proteins have been considered to make the major contribution to milk 


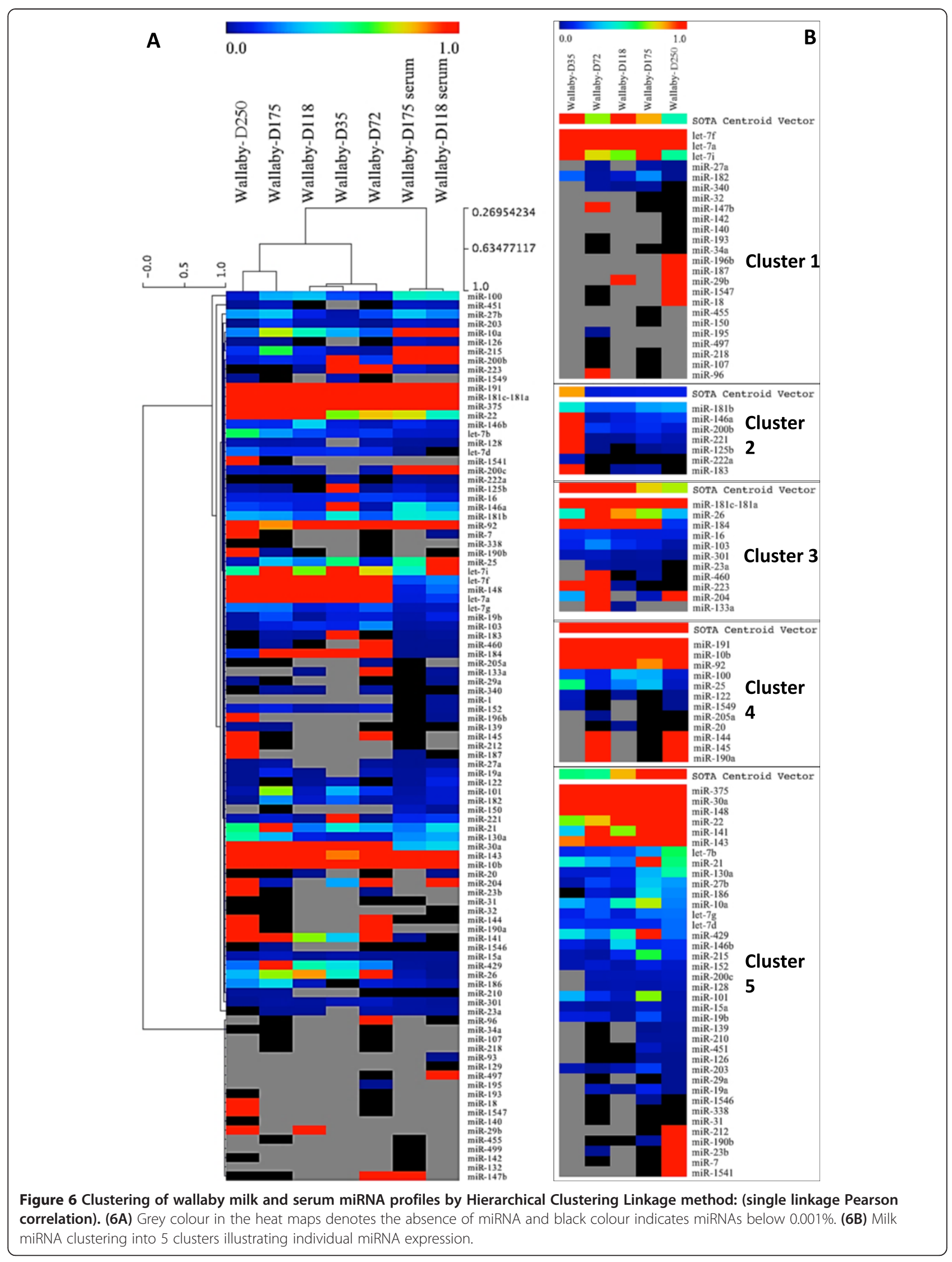


Table 3 Proportion of wallaby milk miRNA in clusters from the Self Organizing Tree Algorithm (SOTA) using relative expression levels across 5 time points of lactation cycle

\begin{tabular}{ccc}
\hline Cluster & miRNA in Cluster & \% of miRNA in Cluster \\
\hline 1 & 24 & $26 \%$ \\
2 & 7 & $8 \%$ \\
3 & 11 & $12 \%$ \\
4 & 12 & $13 \%$ \\
5 & 38 & $41 \%$ \\
\hline
\end{tabular}

bioactivity $[34,40]$. However, newly identified milk RNA components, such as miRNA, represent not only potential markers of mammary gland development and activity during the lactation cycle, but also new putative signaling molecules involved in the programming of young development. However, milk miRNA signaling responses in the suckled young have not yet been well defined. We hypothesised that the long lactation period of the wallaby with significant changes in milk composition would allow the characterisation of interesting dynamic patterns of miRNA expression. Cross-fostering experiments have shown that, when a young is fostered onto a mother at a more advanced stage of lactation, an increased rate of growth and of gut development is observed [41]. This indicates that the temporal regulation of milk composition may contribute to the control of development in young marsupials. Therefore secretory milk miRNA may participate in this process and, as a first step towards an understanding of the biogenesis and functional importance of milk miRNA, our study has highlighted the rich diversity and detailed some aspects of the secretion dynamics of the majority of newly identified marsupial milk miRNAs. One limitation of the study is that, as only minute amount of

Table 4 Milk and serum specific miRNAs in lactating wallaby at day 118 and 175 of lactation

\begin{tabular}{cccc}
\hline Milk & Reads & Blood Serum & Reads \\
\hline miR-107 & 104 & miR-1 & 731 \\
miR-1541 & 36 & miR-129 & 194 \\
miR-1549 & 560 & miR-132 & 29 \\
miR-17-3p & 41 & miR-142 & 34 \\
miR-190a & 86 & miR-187 & 148 \\
miR-200a-5p & 515 & miR-196b & 393 \\
miR-200b & 4927 & miR-214 & 10 \\
miR-200c & 1948 & miR-499 & 29 \\
miR-204 & 58142 & miR-93 & 343 \\
miR-218 & 93 & & \\
miR-23b & 129 & & \\
miR-338 & 119 & & \\
miR-34a & 60 & & \\
\hline
\end{tabular}

Table 5 Highly abundant milk or serum enriched miRNAs

\begin{tabular}{lllll}
\hline miRNAs & D118-Milk & D118-Serum & D175-Milk & D175-serum \\
\hline miR-184* & 8.56 & 0.01 & 1.45 & 0.00 \\
miR-148* $^{*}$ & 8.32 & 0.20 & 14.61 & 0.09 \\
miR-30a* $^{*}$ & 3.36 & 0.37 & 13.67 & 0.31 \\
let-7f* $^{*}$ & 5.371 & 0.238 & 6.04 & 0.168 \\
miR-141* $^{*}$ & 0.684 & 0.002 & 4.962 & 0.01 \\
miR-375* $^{*}$ & 8.225 & 1.202 & 9.782 & 1.487 \\
miR-191* $^{*}$ & 43.83 & 5.77 & 9.66 & 14.51 \\
miR-10a** $^{*}$ & 0.48 & 7.20 & 0.71 & 10.55 \\
miR-10b** $^{*}$ & 3.42 & 69.17 & 3.76 & 55.40 \\
miR-92** $^{*}$ & 2.504 & 2.628 & 0.849 & 4.486 \\
\hline
\end{tabular}

miRNAs* are milk enriched and miRNAs** are serum enriched.

milk could recovered during the earlier stages of lactation (50 to $300 \mu \mathrm{l}$ ) and to minimize cost, single sequencing reactions only were performed at each time point of lactation and it is therefore not possible to estimate biological variation and derive robust statistical models for the analysis of differential expression. To partially compensate for this limitation we have however taken care to normalise the data at the source by pooling milk from different animals $(n \geq 3)$ before RNA extraction and mainly compared highly expressed miRNA to address the major temporal trend of changes of expression patterns during of the full cycle of lactation rather than conduct differential analysis on pairs of samples.

When all known and co-expressed miRNAs were clustered into 5 groups, the highest number of miRNAs fell in a cluster showing a steady increase in expression from early to late lactation. The study suggests a steady increase in the number of miRNAs and a general quantitative increase of a large group of miRNA during the course of marsupial lactation. This general increase correlates with milk production, phases of mammary gland development during lactation in this organism with a complex lactation system, and the development of organs and improved physiological conditions of the young as it grows in the security of the pouch. This group of miRNA may represent markers of mammary gland activity and putative growth signals. In contrast, the lowest number of miRNAs was in a cluster showing a decrease from early to late lactation indicating miRNA in this cluster are prime candidates for signalling early development of the young.

The serum miRNA profiles were significantly different from all milk samples. Some of the miRNAs (mir-10b, miR-10a, miR-215 and miR-150) were most dominantly expressed in wallaby serum samples and were comparatively low in milk samples. This observation points to a mammary gland biogenesis of miRNAs and secretion in milk, rather than transfer from serum. Although further detailed analysis of specific miRNA is needed to characterise the diffusion of 

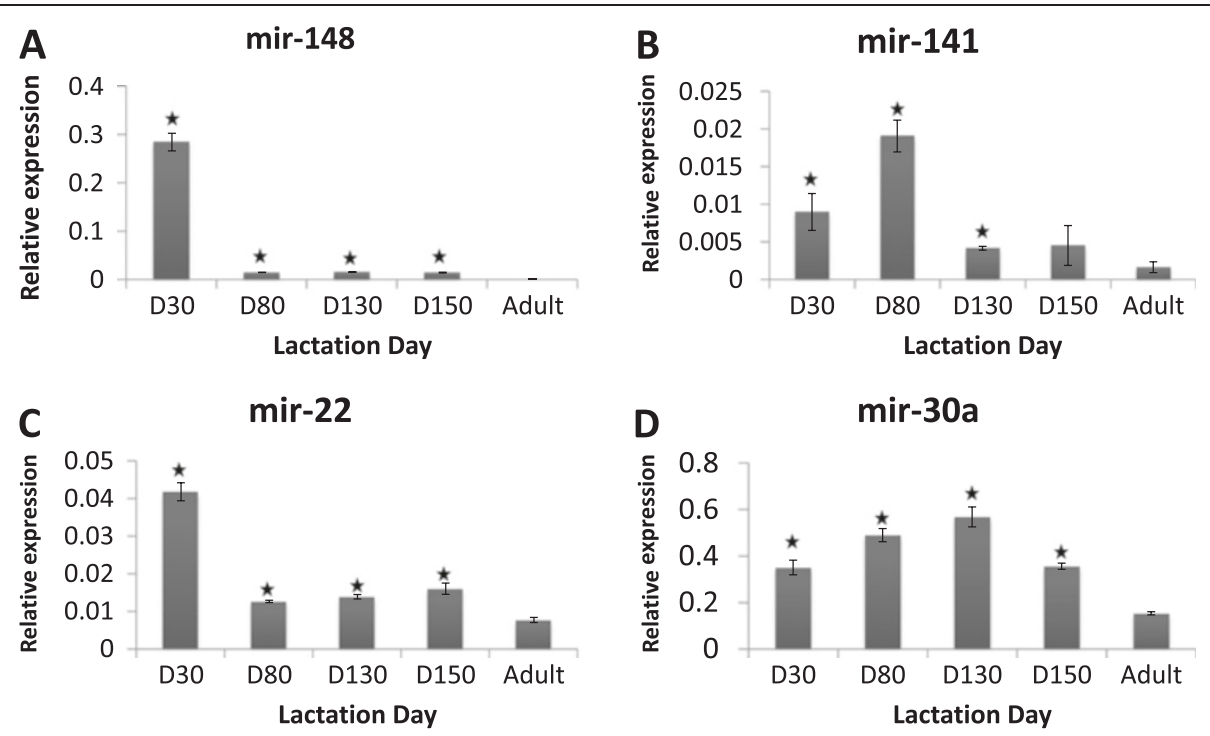

Figure 7 Quantitative PCR of milk related miRNAs in serum of tammar pouch young during lactation. Abundant milk miRNAs (A) mir-148, (B) mir-141, (C) mir-22, and (D) mir-30a were analysed in tammar pouch young and post-suckling neonate blood serum. The expression was relative to control genes (artificial miRNA spikes cel-mir-39 or cel-mir-54) Values are means \pm SD. A significant increase in levels of expression relative to adult $(P<0.05)$.

particular sequences, these results also suggest the possible development of milk quality control and diagnostic tests for the detection of infections or pathologies in lactating mammary glands based on the detection of serum specific miRNA in milk.

The overall comparison of serum and milk miRNA populations indicated the abundant milk miRNAs were miR-148, miR-191, mir-141, let-7b, miR-26, let-7d, miR-30a, miR-184, let-7f and miR-375, and the majority of these miRNAs were differentially expressed during lactation (Table 6). Some miRNAs showed a gradual proportional increase from early lactation to late lactation (miR-375, miR-30a, miR-22, let-7b and miR-130a). In contrast, miR-184, let-7f, miR-101 and miR-182 showed a gradual decrease from early lactation to late lactation. In addition, miR-122, mir-222a and miR-1549 were uniquely expressed at day 35 of early lactation and decreased thereafter. Some of these early temporally secreted milk miRNAs are good candidates for developmental signals during early postnatal life.

\section{Role of miRNA in mammary gland}

The mammary gland is a complex organ, which undergoes extensive morphological changes during the lactation cycle, and this remodelling involves cell differentiation, proliferation and apoptosis [42]. Several factors expressed in the microenvironment by epithelium and mesenchyma play key roles in regulating this process, apart from other external hormones and growth factors secreted by reproductive glands [43]. In general, the basic development process of the mammary gland is similar among marsupials (eg tammar wallaby) and eutherians, but events like cell proliferation and differentiation occur for an extended periods in tammars and, simultaneously, the volume of the mammary gland is increased as lactation progresses and larger quantities of milk are secreted [44]. Recent studies

Table 6 Categories of most abundant miRNAs based on differential expression

\begin{tabular}{|c|c|c|c|c|c|}
\hline Serum specific & Milk specific & Early lactation (Day 35) & Late lactation Day 250 & Gradual decrease & Gradual increases \\
\hline miR-10b & miR-148 & miR-181b & miR-22 & miR-191 & miR-375 \\
\hline miR-10a & miR-141 & miR-222a & miR-200a-3p & miR-184 & miR-30a \\
\hline miR-215 & Let-7b & miR-1549 & & Let-7f & miR-130a \\
\hline \multirow[t]{4}{*}{ miR-150 } & & & & miR-101 & miR-186 \\
\hline & & & & miR-182 & miR-146a \\
\hline & & & & & miR-221 \\
\hline & & & & & miR-125b \\
\hline
\end{tabular}


have indicated an important role for miRNA in mammary gland development [45,46] and breast cancer [47]. For example miR-212 and miR-132 are involved in early mammary gland development by regulating epithelialstromal interactions [45] and the temporal expression of miR-21, miR-205 and miR-200 have potential roles in regulating cell proliferation in the mammary gland during pregnancy $[48,49]$. In tammar miR-148 showed a gradual increase in abundance in milk from early lactation to the end of phase-2B and was the most abundant miRNA in wallaby milk at day-175. It is also among the most highly abundant miRNAs in all other mammalian species tested so far [50] (Lefevre, unpublished data). mir-148 has been shown to be important for growth and development of normal tissues [51,52], and may control growth of mammary epithelial cells. In addition, mir-141, which was also shown to be expressed in tammar milk is involved in the regulation of lactation through STAT5 protein expression [46,53], as in the mammary gland STAT5 plays a central role in mediating several pathways controlled by lactogenic and galactopoietic hormones [54]. Here, we observed high concentration of miR-141 expression was highly expressed in milk samples compared to serum and expression gradually increased as lactation progressed and milk secretion increased. Similarly, mir-146 has been implicated in the regulation of the innate immune response [55] and the gradual increase in the expression of miR-146 during lactation may reflect its activity in protecting the mammary gland from microbial infection such as mastitis. The let-7b miRNA is generally involved in cell proliferation [56] and also regulates the expression of growth hormone receptors (GHR) [57]. The gradual increase in expression of this miRNA during tammar lactation may reflect mammary gland activity associated with cell proliferation and lipid metabolism as lactation progresses [58]. On other hand mir-181, also consistently abundant in all wallaby milk and serum samples, has been implicated in many cellular processes related to the immune system [59] and also in determination of cell fate and invasion [60]. In summary, all these molecules represent non-invasive candidate markers for physiologic and developmental analysis of the lactating mammary gland. More intriguingly, some of these miRNAs might also function in newborns to control growth.

\section{Secretory milk miRNA may regulate growth and development of the neonate}

Based on miRNA expression patterns during lactation and the identification of milk specific miRNAs, we speculate that some of these miRNAs may represent promising candidates to signal specific development of the pouch young. The role of milk miRNAs is being intensely debated in lactation biology. Variation of miRNA profiles may represent changes in the developmental and metabolic activity of the mammary gland during different stages of lactation and may be used further as biomarkers, or may be specifically secreted by the mammary gland to be transported to the newborn as milk bio-actives [50]. This new putative form of signalling and epigenetic programing between the mother and the neonate may use a sophisticated exosomal transport system. The majority of organs in a new-born tammar wallaby are still functionally immature and their postnatal development relies completely on maternal factors supplied through milk [19]. Milk bioactives include growth factors, peptides, fatty acids and hormones. Like other milk bioactives, milk miRNAs may have a crucial role in development due to their participation in gene regulation. Some of the most abundant milk miRNAs are briefly discussed below in relation to their putative functions during development (Table 7).

Three members of the let-7 family (7f, $7 \mathrm{a}$ and $7 \mathrm{i}$ ) were abundant in tammar milk. The let-7 family has been shown to play a significant role during animal development [78]. In tammar milk mir-122 is highly expressed at day 35 and is significantly down-regulated afterward, this miRNA has been reported to control liver development

Table 7 miRNAs differentially expressed in milk and their function during development

\begin{tabular}{|c|c|c|}
\hline miRNA & Function & Reference \\
\hline miR-148 & Growth and development of normal tissues & {$[52,61]$} \\
\hline $\operatorname{miR}-184$ & $\begin{array}{l}\text { Development of central nervous system and regulates the balance between the } \\
\text { neural stem cell proliferation and differentiation }\end{array}$ & {$[62-64]$} \\
\hline let-7b & Neural stem cell differentiation and proliferation & {$[63]$} \\
\hline let-7 s & During embryonic development regulates the timing of terminal differentiation & {$[65,66]$} \\
\hline $\operatorname{miR}-122$ & Liver-specific and key role in liver development & {$[67-69]$} \\
\hline $\operatorname{miR}-22$ & Neural system and erythroid development and maturation & {$[70,71]$} \\
\hline $\operatorname{miR}-375$ & $\begin{array}{l}\text { Highly expressed in hormone secreting organs (pancreas and pituitary gland) and } \\
\text { regulate pancreas organogenesis }\end{array}$ & {$[72-74]$} \\
\hline $\operatorname{miR}-204$ & Lens and retinal development & {$[75,76]$} \\
\hline miR-30 & Kidney development by regulating Xenopus pronephros development & {$[77]$} \\
\hline
\end{tabular}


and may play a role in liver development of pouch young. Gradually increasing miRNA were mir-22, mir-375, mir-30a, let7b and mir-130a and some of these miRNAs have also been involved in animal development. Mir-375 is expressed in organs linked to hormone secretion such as pancreas and pituitary gland and its expression level increases during pancreas organogenesis [72]. Mice mir-375 knockouts exhibit a decrease in the number of $\beta$-cells and an increase of $\alpha$-cells, leading to hyperglycaemia [73]. Perhaps more significantly, this miRNA has been shown to control the establishment of mucosal immunity in the gut via epithelial-T cell crosstalk, as demonstrated by the greater susceptibility to infection of gut specific knockout mice [79]. The large increase of mir-375 in phase 3 of lactation, when the young starts to exit the pouch and add grass to the diet supports the concept of a milk miRNA contribution to the establishment of mucosal immunity in the young. On the other hand, mir-204 is uniquely expressed during early lactation (phase2A) during which the altricial tammar neonate ( 0.4 grams at birth) is subject to intense nervous system and eye development [80,81]. Interestingly, mir-204 regulates lens morphogenesis by controlling the expression of lens placode differentiation gene via the Meis2/Pax6 pathway [75]. Other miRNAs showed a gradual decrease during lactation (mir-184, let-7f, mir-101 and mir-182). mir-184 was highly abundant in tammar milk during early lactation phase-2A until early phase-2B, mir-184 has a significant role in regulating the balance between neural stem cell proliferation and differentiation during development $[62,63]$. In marsupial at birth the central nervous system is at early stages of development and the majority of development takes place during early postnatal life [82]. Therefore, the high expression of miR-184 in tammar milk during early lactation may have potential role in maturation of the central nervous system. Further, the mir-30 family is involved in kidney development by regulating the extension of nephron through cell differentiation and proliferation, by targeting the Xlim1/Lhx1 transcription factor as shown in Xenopus pronephros development [77]. From the expression data we noticed a peak expression of mir-30 in milk after day130 lactation, this may correlate with nephrogenesis in tammar pouch young as their urinary system starts to undergo maturation and become fully functional during late phase $2 \mathrm{~B}$ and is not matured before 140 days (20 weeks) after birth [83].

\section{Transport of milk miRNAs to the pouch young through exosomes}

Our results indicate that milk miRNAs are differentially expressed during tammar lactation and most miRNAs are likely to be secreted by the mammary gland. To better understand how these miRNAs were secreted into milk and the potential mechanism of uptake of milk miRNAs by the suckling young, milk was fractionated by ultracentrifugation and size cut-off column filtration. The results showed that the majority of tammar milk miRNA co-purified together with other small RNA in a fraction enriched in exosome-like vesicles. These vesicules ranged from $30 \mathrm{~nm}$ to $70 \mathrm{~nm}$ in size and appeared round in shape, similar to exosomes reported in milk of eutherians, including bovine [14], porcine [36] and human [84,85] species. These results suggest that miRNAs in tammar milk are likely to be transported through exosome vesicles and potentially play a role in communication of a diversity of potential molecular signal between cells [86]. Further analysis of these exosomal miRNAs revealed they displayed stability under harsh conditions, indicating that milk miRNAs may successfully be transported to the pouch young without degradation and may survive longer in the gut. Therefore, the presence of exosome-like vesicles in milk suggests that these secretory vesicles may participate in the protective packaging and transport of bioactivities and signals to the neonate and during its subsequent development in the pouch. To address this important issue of a new signalling pathway between mother and young, the digestive system of the young needs to be considered. The digestive system of marsupials is very immature at birth [41,87] and therefore tammar milk miRNAs may be absorbed through the premature gut system of tammar pouch young and transferred into the blood of the neonate where they could be detected at high concentration. This is possibly in contrast with a majority of eutherians species where the digestive system is far more mature before birth and, soon after birth, the uptake of macromolecules such as immunoglobulins is rapidly ceased [88-90]. The transfer of milk specific miRNAs to the blood circulation of the neonate was detected for a number of highly concentrated milk miRNA quantified in blood samples from pouch young at different stages of development, in contrast to the blood miRNA content of the post suckling adult stage. It is important to consider that a majority of miRNAs may be produced endogenously by the neonate, and therefore this study focused on miRNAs that were shown to be overexpressed at least a thousand fold in milk compare to the mother serum miRNAs, as known from miRNA sequencing. From the qRT-PCR results it was observed that the majority of milk miRNAs were present at high levels in the blood of neonates compared to adult blood serum. Although these indirect results are preliminary and further studies will be required to demonstrate this process of exosome uptake by the gut, the present study suggests that milk miRNAs are transported after packaging into exosomes (rather than freely floating in milk) and that milk miRNAs may be absorbed by the neonate gut system and enter the blood circulation. It is possible that exosomes carry specific surface receptors to 
attach to the gut cell wall, or that exosomes are digested in the gut where miRNAs are secondarily released along with proteins before absorption by gut cells [91,92]. Alternatively, exosomal vesicles may diffuse passively through the immature gut of the neonate. Further studies are required to address this issue together with further characterisation of the detailed structure, biogenesis and molecular composition of milk exosomes.

\section{Conclusions}

In this study miRNA populations have been quantified in milk of the marsupial tammar wallaby. We have identified suite of marsupial milk miRNAs and describe the major dynamics of milk miRNA secretion during the complex lactation cycle of the tammar wallaby. In this marsupial model of lactation, pronounced temporal variation patterns of milk miRNA composition have revealed miRNA signatures that may be used to clarify the miRNA-dependant regulation of mammary gland activity as well as the relevance of exosomal transport of the molecular miRNA message towards protection and timing of specific developmental stages in the young. We report poor transfer of miRNA from blood into milk in the mother, but provide evidence toward a likely transfer of milk miRNA into the blood stream of the neonate. Demonstrating the dynamics of milk miRNA profiles across the tammar wallaby lactation cycle has highlighted the value of comparative quantitative transcriptomics to improve our understanding of milk composition and, more importantly, has paved the way to address the true potential of milk miRNA functionality and the full impact of milk consumption on health and wellbeing.

\section{Methods}

\section{Ethical approval}

Tammar wallabies (M. eugenii) were maintained in open grassy yards in a breeding colony at Deakin University, Geelong, Victoria (May-August 2012) and CSIRO, Canberra, Australia (June-September 2012). All experimentation was approved by Deakin University and CSIRO Animal Welfare committees.

\section{Milk collection and isolation of miRNA}

Prior to collecting milk, female tammar wallabies were anaesthetised either with an intramuscular injection of $0.2 \mathrm{ml}$ ( $4 \mathrm{mg} / \mathrm{kg}$ body weight) of Zoletil $100^{\circ}$ (Virbac, NSW, Australia) or by inhalation anaesthesia (4\% Isoflurane under oxygen). To optimize milk collection and to induce milk letdown 0.2 IU of Oxytocin-S ${ }^{\bullet}$ (Intervet, Boxmeer, The Netherlands) was administered intramuscularly. Approximately 300-500 $\mu \mathrm{L}$ of milk was collected from each animal by applying gentle pressure to the mammary glands, and it was stored at $-80^{\circ} \mathrm{C}$ until further analysis. To examine the temporal variation of milk miRNA secretion, milk was obtained from mothers at day $35(n=10), 75$ $(n=5)$ (Phase 2A) $118(n=4), 175(n=4)$ (Phase 2B) and $250(n=4)$ (Phase 3$)$ of lactation (some early lactations were interrupted due, in part, to the young failing to reattach to the teat). The milk was thawed on ice and samples collected at particular time point were pooled together. About $1 \mathrm{ml}$ of milk mix was use for RNA isolation. The samples were centrifuged at $5000 \mathrm{xg}$ for $10 \mathrm{~min}$ to isolate the fat and cells from skim. Skim milk was centrifuged at $17,000 \mathrm{xg}$ for $20 \mathrm{~min}$ to isolate any remaining cells and fat. miRNAs were isolated from skim milk using a commercially available miRNA isolation Kit (mirVana ${ }^{\mathrm{Tm}}$ miRNA Isolation Kit, Ambion) and the isolation was performed as instructed in the manufacturer's manual. The miRNA was eluted with $100 \mu \mathrm{l}$ of elution solution provided in the kit. The samples were stored at $-80^{\circ} \mathrm{C}$ until further analysis.

\section{RNA sequencing}

Sequencing libraries were prepared according to the Solexa Small RNA Sample Prep Protocol. Briefly, the RNA was resolved on 15\% polyacrylamide denaturing gels. Gel fragments with a size range of 18-40 nucleotides were excised, and the small RNA fragments were eluted overnight with $0.5 \mathrm{M} \mathrm{NaCl}$ at $4^{\circ} \mathrm{C}$, and precipitated by ethanol. The small RNA was ligated to $5^{\prime}$ and 3' RNA adapters with T4 RNA ligase, transcribed into cDNA by Super-Script II Reverse Transcriptase (Invitrogen) and amplified by 15 PCR cycles using Illumina ${ }^{\text {TM }}$ small RNA primer set that were annealed to the ends of the adapters. The amplified cDNA products were purified and recovered. Finally, Solexa/ Illumina HiSeq sequencing technology was employed to sequence the small RNA samples (BGI, Shenzhen, China). The sequencing data was deposited in the Gene Expression Omnibus (GEO accession GSE58941).

\section{Blood collection and isolation of miRNA}

To compare the miRNA distributions of milk and blood serum of lactating mothers, blood samples were collected from the lateral tail vein of lactating mothers at day $118(n=2)$ and day $175(n=2)$. To analyse miRNAs expression in blood of pouch young during the course of development, pouch young at age of day $30(n=6)$, $80(n=4), 130(n=4) \& 150(n=3)$ and adult (post suckling) $(n=3)$ were collected from lactating mothers and the blood samples were collected immediately after sacrifice. The miRNAs from blood serum were extracted using a miRNeasy Serum/Plasma Kit (QIAGEN) as instructed in the kit manual. Milk miRNAs were quantified using qRT-PCR. Two exogenous miRNAs spikes of chemically synthesized cel-miR-39 and cel-miR-54 (miRNA sequences from Caenorhabditis elegans) were simultaneously used as control genes. 


\section{Analysis of RNA-seq data}

Raw FastQ sequence files from the sequencer were cleaned and adaptors were trimmed using FastQ and FastX programs. Because a complete annotated chromosomal sequence of wallaby is not yet available, the closely related Opossum genome reference and annotations were downloaded from Ensemble (Monodelphis_domestica. BROADO5.67). Chromosomal sequences were indexed using Bowtie 2 software and wallaby datasets read mapping was performed against Mondom5 genome assembly using Bowtie2 [93]. Genome alignments were visualized and further investigated in SeqMonk (version 0.24.1). A specialized miRNA annotation tool miRanalyzer was used for the identification of miRNA populations in small RNAs sequence libraries. This tool employs the fast read aligner Bowtie to first align sequences to known miRNAs from miRbase version 19 [94], then to noncoding RNA sequence from Rfam and, finally the remaining sequences are investigated in the context of the genome reference. miRNA target predictions were done on miRNA_Targets database (http://mamsap.it.deakin.edu. au/ amitkuma/mirna_targetsnew/index.html) [95]. Ontology analysis was performed using David Bioinformatics Ontology Database.

\section{Data accession numbers}

The data sets supporting the results of this article are available in the GEO database, accession number for the data set is GSE58941.

\section{CDNA synthesis and q-PCR for miRNA}

Stem-loop primers were used for accurate and sensitive detection of miRNAs [96]. miRNA sequences were retrieved from the miRBase sequence database (http://www.mirbase. org/cgi-bin/browse.pl) to design stem-loop and forward primers. The reverse primer used for RT-PCR was always the universal reverse primer (see Additional file 4). The RT mixture included the combination of RNA (100 ng), $10 \mathrm{mM}$ dNTP, stem-loop primer $(1 \mu \mathrm{M})$ and nuclease free water up to $15 \mu \mathrm{l}$ total volume. The mixture was incubated at $65^{\circ} \mathrm{C}$ for 5 minutes and immediately transferred to ice for 2 minutes. The reaction mix $(15 \mu \mathrm{l})$ of the first RT synthesis, 5X First stand buffer $(4 \mu \mathrm{l}), 0.1 \mathrm{~m}$ DTT $(2 \mu), 0.25 \mu \mathrm{l}$ RNaseOUT (40 units/ $\mu \mathrm{l}$ ) and $0.5 \mu \mathrm{l}$ Superscript III (200 units/ $\mu$ l) was incubated in a thermocycler for 30 minutes at $16^{\circ} \mathrm{C}$, followed by $30^{\circ} \mathrm{C}$ for 30 seconds, $40^{\circ} \mathrm{C}$ for 30 seconds and $50^{\circ} \mathrm{C}$ for 1 second for a total of 60 cycles. Reactions were terminated by incubating at $85^{\circ} \mathrm{C}$ for 5 minutes. Real-time PCR was performed using an SsoFast EvaGreen Supermix (Bio-Rad) and CFX96TM Real-Time PCR Detection System (Bio-Rad). The PCR mixture contained cDNA from RT synthesis, $1 \mu \mathrm{M}$ forward primer, $1 \mu \mathrm{M}$ universal reverse primer, and $7 \mu \mathrm{l}$ SYBER Green master mix and made to $14 \mu \mathrm{l}$ with nuclease free water. All samples were run as triplicates. The expression levels of target miRNAs were normalized to artificial miRNA Spikes cel-mir-39 (tcaccgggtgtaaatcagcttg) and cel-mir-54 (tacccgtaatcttcataatccgag).

\section{Exosome isolation from tammar milk}

This isolation process was performed at $4{ }^{\circ} \mathrm{C}$. The milk samples were thawed on ice and centrifuged at $5000 \mathrm{xg}$ for $10 \mathrm{~min}$ to isolate the fat and cells. The samples were then centrifuged at $17,000 \mathrm{xg}$ for $30 \mathrm{~min}$ to remove the excess cell debris and fat. Samples were subsequently subjected to ultracentrifugation at 50,000 $\mathrm{xg}$ for $60 \mathrm{~min}$ to remove casein micelles and collect the whey fraction. The whey fraction was filtered through a $0.4 \mu \mathrm{m}$ PVDF filter and then a $0.2 \mu \mathrm{m}$ PVDF filter to remove any further complex particles, and also to allow free flow of the sample through in the subsequent filtration step. The filtrate was loaded on to a $100 \mathrm{kDa}$ filter column (Vivaspin 6, Sartorius AG) and centrifuged at $3900 \mathrm{xg}$ for $90 \mathrm{~min}$. The flowthrough purified milk exosome fraction was collected and stored at $-80^{\circ} \mathrm{C}$.

\section{Small RNA profiling on the Bio-analyser}

miRNA was isolated from the milk exosome fraction and subjected to bio-analyser profiling to analyse the distribution of small RNA and estimate miRNA concentration using an Agilent 2100 Bioanalyzer and a Small RNA isolation kit (Agilent Technologies Australia). The experiment was performed as directed in the kit manual and $1 \mu \mathrm{l}$ of the RNA preparation was used for the analysis.

\section{Electron-microscope (TEM) analysis of exosomes}

Purified exosomes from milk samples were analysed using TEM. A drop of sample was placed on parrafilm and fixed with $2.5 \%$ gluteraldehyde for 10 minutes at room temperature. A copper grid (Formvar film on 300 mesh $\mathrm{Cu}$ Grids) was placed on the drop for $30 \mathrm{~min}$. The sample grid was washed twice with deionized water to remove the excess fixative and stained with Nano-Wan (Nanoprobes). Samples were examined under a JEM-2100 LaB6 Transmission Electron Microscope.

\section{Stability of milk exosome miRNAs}

The stability of milk miRNAs in the exosomal fraction were examined under the following conditions: (A) $\mathrm{pH} 1.5$ for 5 and 60 minutes; (B) $\mathrm{pH} 4$ for 5 and 60 minutes, the $\mathrm{pH}$ was altered by stepwise addition of $1 \mathrm{~N} \mathrm{HCL}$ aliquots as required and (C) treatment with RNase was for 5 and 30 minutes at $37^{\circ} \mathrm{C}$. Two chemically synthesised, free exogenous miRNAs which have no sequence similarity to tammar milk miRNAs (cel-mir-39 and cel-mir-54) were included with the exosomes as a control. The miRNAs were isolated and quantified by q-PCR as described above. 


\section{Statistical analysis}

The Q-PCR analysis were represented as mean \pm standard error of mean (SEM) and the expression was statistically analysed by applying student $t$-Test. Differential expression was considered significant when $\mathrm{P}<0.05$.

\section{Additional files}

Additional file 1: Table S1. Table listing the miRNAs expression in tammar wallaby milk and serum. Normalized miRNA expression of mapped reads in respective milk and serum samples. The empty boxes represent absence and 0 represents low expression of the respective miRNAs

Additional file 2: Table S2. miRNAs found in individual samples of milk and serum from tammar females.

Additional file 3: Figure S1. Venn diagrams of the distribution of miRNAs found in milk and serum at lactation days 118 and 175 .

Additional file 4: Table S4. Primer sequences used for miRNA quantification by PCR.

\section{Competing interests}

I declare that the authors have no competing interests as defined in the instruction to authors of the journal.

\section{Authors' contributions}

VM performed all analysis except where otherwise noted. LAH was involved in sample collection. CL, AK and VM performed miRNA sequence analysis and discussing the results. $\mathrm{VM}, \mathrm{CL}$ and $\mathrm{KRN}$ were involved in designing the study. CL, KN, LH and JAS contributed in commenting on the manuscript. All authors read and approved the final manuscript.

\section{Acknowledgements}

We thank Lyn Hinds, Steve Henry and Sameer Sharma from CSIRO, Canberra, in providing the samples. We also thanks Deakin animal house faculty in maintain the wallaby facility. We cherish all fellow lab mates from Kevin Nicholas lab. We would like to thanks GATES foundation for funding this project. Modepalli. $V$ and Kumar. A are funded by the Deakin University PhD program.

\section{Author details}

${ }^{1}$ School of medicine, Deakin University, Pigdons Road, Geelong, Vic, Australia. ${ }^{2}$ CSIRO Ecosystem Sciences, GPO Box 1700, Canberra, Act 2601, Australia.

\section{Received: 6 August 2014 Accepted: 30 October 2014}

Published: 23 November 2014

\section{References}

1. Hwang HW, Mendell JT: MicroRNAs in cell proliferation, cell death, and tumorigenesis. Brit J Cancer 2006, 94(6):776-780

2. Song L, Tuan RS: MicroRNAs and cell differentiation in mammalian development. Birth Defects Res C Embryo Today 2006, 78(2):140-149.

3. Zhou Q, Li MZ, Wang XY, Li QZ, Wang T, Zhu Q, Zhou XC, Wang X, Gao XL, Li XW: Immune-related MicroRNAs are abundant in breast milk exosomes. Int J Biol Sci 2012, 8(1):118-123.

4. Michael A, Bajracharya SD, Yuen PST, Zhou H, Star RA, Illei GG, Alevizos I: Exosomes from human saliva as a source of microRNA biomarkers. Oral Dis 2010, 16(1):34-38.

5. Caby MP, Lankar D, Vincendeau-Scherrer C, Raposo G, Bonnerot C: Exosomal-like vesicles are present in human blood plasma. Int Immunol 2005, 17(7):879-887.

6. Pisitkun T, Shen RF, Knepper MA: Identification and proteomic profiling of exosomes in human urine. Proc Natl Acad Sci U S A 2004, 101(36):13368-13373.

7. Kosaka N, Yoshioka Y, Hagiwara K, Tominaga N, Ochiya T: Functional analysis of exosomal microRNA in cell-cell communication research Methods Mol Biol 2013, 1024:1-10
8. Camussi G, Deregibus MC, Bruno S, Cantaluppi V, Biancone L: Exosomes/ microvesicles as a mechanism of cell-to-cell communication. Kidney Int 2010, 78(9):838-848.

9. Ge Q, Zhou Y, Lu J, Bai Y, Xie X, Lu Z: MiRNA in plasma exosome is stable under different storage conditions. Molecules 2014, 19(2):1568-1575.

10. Munch EM, Harris RA, Mohammad M, Benham AL, Pejerrey SM, Showalter L, Hu M, Shope CD, Maningat PD, Gunaratne PH, Haymond M, Aagaard K: Transcriptome profiling of microRNA by next-Gen deep sequencing reveals known and novel miRNA species in the lipid fraction of human breast milk. PLOS ONE 2013, 8(2):e50564.

11. Donovan SM, Odle J: Growth-factors in milk as mediators of infant development. Annu Rev Nutr 1994, 14:147-167.

12. Nicholas KR: Asynchronous dual lactation in a marsupial, the tammar wallaby (Macropus-Eugenii). Biochem Biophys Res Commun 1988, 154(2):529-536.

13. Kosaka $\mathrm{N}$, Izumi $\mathrm{H}$, Sekine $\mathrm{K}$, Ochiya T: microRNA as a new immune-regulatory agent in breast milk. Silence 2010, 1(1):7.

14. Hata T, Murakami K, Nakatani H, Yamamoto Y, Matsuda T, Aoki N: Isolation of bovine milk-derived microvesicles carrying mRNAs and microRNAs. Biochem Biophys Res Commun 2010, 396(2):528-533.

15. Chen T, Xi Q-Y, Ye R-S, Cheng X, Qi Q-E, Wang S-B, Shu G, Wang L-N, Zhu X-T, Jiang Q-Y, Zhang Y-L: Exploration of microRNAs in porcine milk exosomes. Bmc Genomics 2014, 15(1):100.

16. Ji ZB, Wang GZ, Xie ZJ, Zhang CL, Wang JM: Identification and characterization of microRNA in the dairy goat (Capra hircus) mammary gland by Solexa deep-sequencing technology. Mol Biol Rep 2012, 39(10):9361-9371.

17. Wienholds E, Kloosterman WP, Miska E, Alvarez-Saavedra E, Berezikov E, de Bruijn E, Horvitz HR, Kauppinen S, Plasterk RH: MicroRNA expression in zebrafish embryonic development. Science 2005, 309(5732):310-311.

18. Laurent LC: MicroRNAs in embryonic stem cells and early embryonic development. J Cell Mol Med 2008, 12(6A):2181-2188.

19. Trott JF, Simpson KJ, Moyle RL, Hearn CM, Shaw G, Nicholas KR, Renfree MB: Maternal regulation of milk composition, milk production, and pouch young development during lactation in the tammar wallaby (Macropus eugenii). Biol Reprod 2003, 68(3):929-936.

20. Tyndale-Biscoe CH, Janssens PA: The Developing Marsupial: Models for Biomedical Research. Berlin: Springer; 1988.

21. Jenness R: Lactational performance of various mammalian-species. J Dairy Sci 1986, 69(3):869-885.

22. Renfree MB: Life in the pouch: womb with a view. Reprod Fert Develop 2006, 18(7):721-734.

23. Brennan AJ, Sharp JA, Digby MR, Nicholas KR: The tammar wallaby: a model to examine endocrine and local control of lactation. IUBMB Life 2007, 59(3):146-150.

24. Deane EM, Cooper DW: Immunology of pouch young marsupials. I. Levels of immunoglobulin transferrin and albumin in the blood and milk of euros and wallaroos (hill kangaroos:, marsupialia). Dev Comp Immunol 1984, 8(4):863-876

25. Tizard I: The protective properties of milk and colostrum in non-human species. Adv Nutr Res 2001, 10:139-166.

26. Merchant JC, Sharman GB: Observations on the attatchment of marsupial pouch young to the teats and on the rearing of pouch young by foster-mothers of the same or different species. Aust J Zoo/ 1966, 14(4):593-609.

27. Green B, Krause WJ, Newgrain K: Milk composition in the North American opossum (Didelphis virginiana). Comp Biochem Physiol B Biochem Mol Biol 1996, 113(3):619-623.

28. Bird PH, Hendry KA, Shaw DC, Wilde CJ, Nicholas KR: Progressive changes in milk protein gene expression and prolactin binding during lactation in the tammar wallaby (Macropus eugenii). J Mol Endocrinol 1994, 13(2):117-125.

29. Kevin RN: Asynchronous dual lactation in a marsupial, the tamma wallaby (Macropus eugenii). Biochem Bioph Res Co 1988, 154(2):529-536.

30. Ward KL, Renfree MB: Effects of progesterone on parturition in the tammar. Macropus eugenii J Reprod Fertil 1984, 72(1):21-28.

31. Messer M, Nicholas KR: Biosynthesis of marsupial milk oligosaccharides characterization and developmental-changes of 2 galactosyltransferases in lactating mammary-glands of the tammar wallaby. Macropus-Eugenii Biochim Biophys Acta 1991, 1077(1):79-85. 
32. Nicholas K, Simpson K, Wilson M, Trott J, Shaw D: The Tammar Wallaby: A Model to Study Putative Autocrine-Induced Changes in Milk Composition. J Mammary Gland Biol Neoplasia 1997, 2(3):299-310.

33. Green B, Griffiths M, Leckie RM: Qualitative and quantitative changes in milk fat during lactation in the tammar wallaby (Macropus eugenii). Aust J Biol Sci 1983, 36(5-6):455-461.

34. Nicholas K, Sharp J, Watt A, Wanyonyi S, Crowley T, Gillespie M, Lefevre C: The tammar wallaby: a model system to examine domain-specific delivery of milk protein bioactives. Semin Cell Dev Biol 2012, 23(5):547-556.

35. Sharp JA, Lefèvre C, Nicholas KR: Molecular evolution of monotreme and marsupial whey acidic protein genes. Evol Dev 2007, 9(4):378-392.

36. Gu Y, Li M, Wang T, Liang Y, Zhong Z, Wang X, Zhou Q, Chen L, Lang $Q$, He Z, Chen XH, Gong JJ, Gao XL, Li XW, Lv XB: Lactation-related microRNA expression profiles of porcine breast milk exosomes. Plos One 2012, 7(8):e43691.

37. Greenhill C: Nutrition: drinking cow's milk alters vitamin D and iron stores in young children. Nat Rev Endocrinol 2013, 9(3):126.

38. Messer M, Kerry KR: Milk carbohydrates of the echidna and the platypus. Science 1973, 180(4082):201-203.

39. Ballard O, Morrow AL: Human milk composition nutrients and bioactive factors. Pediatr Clin N Am 2013, 60(1):49-+.

40. Wada $Y$, Lönnerdal B: Bioactive peptides derived from human milk proteins - mechanisms of action. J Nutr Biochem 2014, 25(5):503-514.

41. Kwek JH, longh RD, Digby MR, Renfree MB, Nicholas KR, Familari M: Cross-fostering of the tammar wallaby (Macropus eugenii) pouch young accelerates fore-stomach maturation. Mech Dev 2009, 126(5-6):449-463.

42. Knight $\mathrm{CH}$, Peaker M: Development of the mammary gland. $J$ Reprod Fertil 1982, 65(2):521-536

43. Macias $H$, Hinck L: Mammary gland development. Wiley Interdiscip Rev Dev Biol 2012, 1(4):533-557.

44. Findlay L: The mammary-glands of the tammar wallaby (macropus-eugenii) during pregnancy and lactation. J Reprod Fertil 1982, 65(1):59.

45. Ucar A, Vafaizadeh V, Jarry H, Fiedler J, Klemmt PAB, Thum T, Groner B, Chowdhury K: miR-212 and miR-132 are required for epithelial stromal interactions necessary for mouse mammary gland development. Nat Genet 2010, 42(12):1101-U1100.

46. Li Z, Liu HY, Jin XL, Lo LJ, Liu JX: Expression profiles of microRNAs from lactating and non-lactating bovine mammary glands and identification of miRNA related to lactation. BMC Genomics 2012, 13:731.

47. Singh R, Mo YY: Role of microRNAs in breast cancer. Cancer Biol Ther 2013, 14(3):201-212

48. Galio L, Droineau S, Yeboah P, Boudiaf H, Bouet S, Truchet S, Devinoy E: MicroRNA in the ovine mammary gland during early pregnancy: spatial and temporal expression of miR-21, miR-205, and miR-200. Physiol Genomics 2013, 45(4):151-161.

49. Nagaoka K, Zhang HL, Watanabe G, Taya K: Epithelial cell differentiation regulated by MicroRNA-200a in mammary glands. Plos One 2013, 8(6):e65127.

50. Kumar A, Wong AKL, Tizard ML, Moore RJ, Lefèvre C: miRNA_targets: a database for miRNA target predictions in coding and non-coding regions of mRNAs. Genomics 2012, 100(6):352-356.

51. Gailhouste L, Gomez-Santos L, Hagiwara K, Hatada I, Kitagawa N, Kawaharada K, Thirion M, Kosaka N, Takahashi R, Shibata T, Miyajima A, Ochiya T: miR-148a plays a pivotal role in the liver by promoting the hepatospecific phenotype and suppressing the invasiveness of transformed cells. Hepatology 2013, 58(3):1153-1165.

52. Chen $Y$, Song $Y X$, Wang ZN: The MicroRNA-148/152 family: multi-faceted players. Mol Cancer 2013, 12(1):43.

53. Yang J, Kennelly JJ, Baracos VE: The activity of transcription factor Stat5 responds to prolactin, growth hormone, and IGF-I in rat and bovine mammary explant culture. J Anim Sci 2000, 78(12):3114-3125.

54. Liu XW, Robinson GW, Wagner KU, Garrett L, WynshawBoris A Hennighausen L: Stat5a is mandatory for adult mammary gland development and lactogenesis. Gene Dev 1997, 11(2):179-186.

55. Labbaye C, Testa U: The emerging role of MIR-146A in the control of hematopoiesis, immune function and cancer. J Hematol Oncol 2012, 5:13.

56. Schultz J, Lorenz P, Gross G, Ibrahim S, Kunz M: MicroRNA let-7b targets important cell cycle molecules in malignant melanoma cells and interferes with anchorage-independent growth. Cell Res 2008, 18(5):549-557.

57. Lin SM, Li HM, Mu HP, Luo W, Li Y, Jia XZ, Wang SB, Jia XL, Nie QH, Li YG, Zhang $X Q$ : Let-7b regulates the expression of the growth hormone receptor gene in deletion-type dwarf chickens. BMC Genomics 2012, 13:306.

58. Wang M, Moisa S, Khan MJ, Wang J, Bu D, Loor JJ: MicroRNA expression patterns in the bovine mammary gland are affected by stage of lactation. J Dairy Sci 2012, 95(11):6529-6535.

59. Henao-Mejia J, Williams A, Goff Loyal A, Staron M, Licona-Limón P Kaech Susan M, Nakayama M, Rinn John L, Flavell Richard A: The MicroRNA miR-181 is a critical cellular metabolic rheostat essential for NKT cell ontogenesis and lymphocyte development and homeostasis. Immunity 2013, 38(5):984-997.

60. Neel JC, Lebrun JJ: Activin and TGFbeta regulate expression of the microRNA-181 family to promote cell migration and invasion in breast cancer cells. Cellular signalling 2013, 25(7):1556-1566.

61. Guo SL, Peng Z, Yang X, Fan KJ, Ye H, Li ZH, Wang Y, Xu XL, Li J, Wang YL, Teng $Y$, Yang $X$ : miR-148a promoted cell proliferation by targeting p27 in gastric cancer cells. Int J Biol Sci 2011, 7(5):567-574.

62. Li P, Peng J, Hu J, Xu Z, Xie W, Yuan L: Localized expression pattern of miR-184 in Drosophila. Mol Biol Rep 2011, 38(1):355-358.

63. Liu CM, Teng ZQ, Santistevan NJ, Szulwach KE, Guo WX, Jin P, Zhao XY: Epigenetic regulation of miR-184 by MBD1 governs neural stem cell proliferation and differentiation. Cell Stem Cell 2010, 6(5):433-444.

64. McKiernan RC, Jimenez-Mateos EM, Sano T, Bray I, Stallings RL, Simon RP, Henshall DC: Expression profiling the microRNA response to epileptic preconditioning identifies miR-184 as a modulator of seizure-induced neuronal death. Exp Neurol 2012, 237(2):346-354.

65. Großhans H, Johnson T, Reinert KL, Gerstein M, Slack FJ: The temporal patterning MicroRNA let-7 regulates several transcription factors at the larval to adult transition in C. elegans. Dev Cell 2005, 8(3):321-330.

66. Reinhart BJ, Slack FJ, Basson M, Pasquinelli AE, Bettinger JC, Rougvie AE, Horvitz HR, Ruvkun G: The 21-nucleotide let-7 RNA regulates developmental timing in Caenorhabditis elegans. Nature 2000, 403(6772):901-906.

67. Filipowicz W, Großhans H: The Liver-Specific MicroRNA miR-122: Biology and Therapeutic Potential. In Epigenetics and Disease, Volume 67. Edited by Gasser SM, Li E. Picassoplatz 4, 4052 Basel, Switzerland: Springer Basel AG; 2011:221-238. http://www.springer.com/gp/about-springer/companyinformation/locations/springer-basel-ag.

68. Xu H, He J-H, Xiao Z-D, Zhang Q-Q, Chen Y-Q, Zhou H, Qu L-H: Liver-enriched transcription factors regulate MicroRNA-122 that targets CUTL1 during liver development. Hepatology 2010, 52(4):1431-1442.

69. Wu X, Wu SQ, Tong L, Luan TA, Lin LX, Lu SL, Zhao WR, Ma QQ, Liu HM, Zhong ZH: miR-122 affects the viability and apoptosis of hepatocellular carcinoma cells. Scand J Gastroentero 2009, 44(11):1332-1339.

70. Jovicic A, Zaldivar Jolissaint JF, Moser R, Silva Santos MF, Luthi-Carter R: MicroRNA-22 (miR-22) overexpression is neuroprotective via general anti-apoptotic effects and may also target specific Huntington's disease-related mechanisms. Plos One 2013, 8(1):e54222.

71. Choong ML, Yang HH, McNiece I: MicroRNA expression profiling during human cord blood-derived CD34 cell erythropoiesis. Exp Hematol 2007, 35(4):551-564.

72. Kloosterman WP, Lagendijk AK, Ketting RF, Moulton JD, Plasterk RHA: Targeted inhibition of miRNA maturation with morpholinos reveals a role for miR-375 in pancreatic islet development. Plos Biol 2007, 5(8):1738-1749.

73. Poy MN, Hausser J, Trajkovski M, Braun M, Collins S, Rorsman P, Zavolan M, Stoffel M: miR-375 maintains normal pancreatic $\alpha$ - and $\beta$-cell mass. Proc Natl Acad Sci 2009, 106(14):5813-5818.

74. Avnit-Sagi T, Kantorovich L, Kredo-Russo S, Hornstein E, Walker MD: The promoter of the pri-miR-375 gene directs expression selectively to the endocrine pancreas. Plos One 2009, 4(4):e5033.

75. Conte I, Carrella S, Avellino R, Karali M, Marco-Ferreres R, Bovolenta P, Banfi S: miR-204 is required for lens and retinal development via Meis2 targeting. Proc Natl Acad Sci 2010, 107(35):15491-15496.

76. Avellino $R$, Carrella S, Pirozzi M, Risolino M, Salierno FG, Franco $P$, Stoppelli $P$, Verde P, Banfi S, Conte I: miR-204 targeting of Ankrd13A controls both mesenchymal neural crest and lens cell migration. Plos One 2013, 8(4):e61099.

77. Agrawal $R$, Tran $U$, Wessely $O$ : The miR-30 miRNA family regulates Xenopus pronephros development and targets the transcription factor Xlim1/Lhx1. Development 2009, 136(23):3927-3936.

78. Büssing I, Slack FJ, Großhans H: let-7 microRNAs in development, stem cells and cancer. Trends Mol Med 2008, 14(9):400-409. 
79. Biton M, Levin A, Slyper M, Alkalay I, Horwitz E, Mor H, Kredo-Russo S, Avnit-Sagi T, Cojocaru G, Zreik F, Bentwich Z, Poy MN, Artis D, Walker MD, Hornstein E, Pikarsky E, Ben-Neriah Y: Epithelial microRNAs regulate gut mucosal immunity via epithelium-T cell crosstalk. Nat Immunol 2011, 12(3):239-U275.

80. Mark RF, Marotte LR: Australian marsupials as models for the developing mammalian visual system. Trends Neurosci 1992, 15(2):51-57.

81. Jellinger KA: The neurobiology of Australian marsupials: brain evolution in the other mammalian radiation. Eur J Neurol 2011, 18(5):e52-e52.

82. Saunders N: Marsupials as Models for Studies of Development and Regeneration of the Central Nervous System. In Marsupial Biology: Recent Research, new Perspectives. LA SNH: University of New South Wales Press Ltd; 1997:380-405

83. Wilkes $G$, Janssens $P$ : Development of urine concentrating ability in pouch young of a marsupial, the tammar wallaby (Macropus eugenii). J Comp Physiol B 1986, 156(4):573-582.

84. Admyre C, Johansson SM, Qazi KR, Filen JJ, Lahesmaa R, Norman M, Neve EPA, Scheynius A, Gabrielsson S: Exosomes with immune modulatory features are present in human breast milk. J Immunol 2007, 179(3):1969-1978.

85. Lasser C, Alikhani VS, Ekstrom K, Eldh M, Paredes PT, Bossios A, Sjostrand M, Gabrielsson S, Lotvall J, Valadi H: Human saliva, plasma and breast milk exosomes contain RNA: uptake by macrophages. J Trans/ Med 2011, 9:9.

86. Creemers EE, Tijsen AJ, Pinto YM: Circulating MicroRNAs: novel biomarkers and extracellular communicators in cardiovascular disease? Circ Res 2012, 110(3):483-495.

87. Old JM, Deane EM: The lymphoid and immunohaematopoietic tissues of the embryonic brushtail possum (Trichosurus vulpecula). Anat Embryol 2003, 206(3):193-197.

88. Westrom BR, Svendsen J, Ohlsson BG, Tagesson C, Karlsson BW: Intestinal transmission of macromolecules (BSA and FITC-labelled dextrans) in the neonatal pig. Influence of age of piglet and molecular weight of markers. Biol Neonate 1984, 46(1):20-26.

89. Teichberg S, Wapnir RA, Moyse J, Lifshitz F: Development of the neonatal rat small intestinal barrier to nonspecific macromolecular absorption.2. Role of dietary corticosterone. Pediatr Res 1992, 32(1):50-57.

90. Lecce JG, Broughto CW: Cessation of uptake of macromolecules by neonatal guinea-pig, hamster and rabbit intestinal epithelium (Closure) and transport into blood. J Nutr 1973, 103(5):744-750.

91. van Niel G, Heyman M: II. Intestinal epithelial cell exosomes: perspectives on their structure and function. Am J Physiol Gastrointest Liver Physiol 2002, 283(2):G251-G255.

92. $\mathrm{Hu} \mathrm{G}$, Drescher KM, Chen X: Exosomal miRNAs: biological properties and therapeutic potential. Front Genet 2012, 3:56.

93. Meunier J, Lemoine F, Soumillon M, Liechti A, Weier M, Guschanski K, Hu H, Khaitovich P, Kaessmann H: Birth and expression evolution of mammalian microRNA genes. Genome Res 2013, 23(1):34-45.

94. Barrett T, Troup DB, Wilhite SE, Ledoux P, Evangelista C, Kim IF, Tomashevsky M, Marshall KA, Phillippy KH, Sherman PM, Muertter RN, Holko M, Ayanbule O, Yefanov A, Soboleva A: NCBI GEO: archive for functional genomics data sets-10 years on. Nucleic Acids Res 2011, 39(Database issue):D1005-D1010.

95. Amit Kumar LB, Kuruppath S, Ngo KP, Nicholas KR, Lefèvre C: The Emerging Role of Micro-RNAs in the Lactation Process. In Lactation: Natural Processes, Physiological Responses and Role in Maternity. Edited by Gutierrez LMRCDCO. [Hauppauge] New York: Nova Biomedical: Nova Science Publishers Inc; 2012.

96. Varkonyi-Gasic E, Wu RM, Wood M, Walton EF, Hellens RP: Protocol: a highly sensitive RT-PCR method for detection and quantification of microRNAs. Plant Methods 2007, 3:12.

doi:10.1186/1471-2164-15-1012

Cite this article as: Modepalli et al:: Differential temporal expression of milk miRNA during the lactation cycle of the marsupial tammar wallaby (Macropus eugenii). BMC Genomics 2014 15:1012.

\section{Submit your next manuscript to BioMed Central and take full advantage of:}

- Convenient online submission

- Thorough peer review

- No space constraints or color figure charges

- Immediate publication on acceptance

- Inclusion in PubMed, CAS, Scopus and Google Scholar

- Research which is freely available for redistribution

Submit your manuscript at www.biomedcentral.com/submit
C Biomed Central 